\title{
B3010: a boosted TSI 3010 condensation particle counter for airborne studies
}

\author{
David Picard $^{1}$, Michel Attoui ${ }^{2}$, and Karine Sellegri ${ }^{1}$ \\ ${ }^{1}$ LaMP, CNRS, Université Clermont Auvergne, Clermont-Ferrand, France \\ ${ }^{2}$ LISA, CNRS, Université Paris Est à Créteil, Créteil, France
}

Correspondence: David Picard (d.picard@opgc.univ-bpclermont.fr)

Received: 20 July 2018 - Discussion started: 14 September 2018

Revised: 28 March 2019 - Accepted: 8 April 2019 - Published: 26 April 2019

\begin{abstract}
In the present paper, we expose how we boosted the performance of a commercial condensation particle counter (CPC) model TSI 3010 to detect particles as small as $1.5 \mathrm{~nm}$ while preserving the robustness and reliability of the original instrument. The TSI 3010 was selected because of our deep knowledge of its internal workings and its large incorporated butanol reservoir that allows continuous operation for several hours without refill, which is well suited to airborne operation. Aside from this, it is still pretty easy to buy instruments from the TSI 3010 family from companies that specialize in used scientific instrument retail. The CPC described in this study is called B3010 hereafter, where the "B" stands for boosted. We provide an evaluation of its performances down to $1 \mathrm{~nm}$ using standard calibration methods and comparisons with ultrafine CPCs (TSI 3025 and TSI 3776), as well as with its original version. One important application of the B3010 is for high-altitude measurement stations and airborne studies, the instrument's detection efficiency was quantified for various inlet flow rates and pressures.
\end{abstract}

\section{Introduction}

\subsection{Scientific background}

It is now widely acknowledged that atmospheric particles have an impact on climate and health. Their concentration in the atmosphere is largely determined by their sources, which can be primary (mechanically emitted) or secondary (from a gas-to-particle conversion process within the atmosphere). Among the formation pathways of secondary aerosols, nucleation is the process responsible for the formation of new nanoparticle clusters (as opposed to the process of condensation onto preexisting particles). Triggered by photochemical processes, oxidized lower-volatility products are formed, of which some have the properties of nucleating into new particulate clusters. Once particle clusters are formed by nucleation, they may be lost on preexisting particles via coagulation if they do not rapidly grow to larger sizes by condensation of less volatile but more abundant species. The processes of nucleation and early growth lead to the occurrence of new particle formation (NPF) in the atmosphere. NPF occurs over several hours and is considered responsible for generation of a large number of aerosols at the global scale (Spracklen et al., 2006). With the development of instruments detecting particles of nanometric size, NPF events have been observed in a growing number of environments (Kulmala et al., 2004).

In particular, at high altitudes, NPF events have been recorded with a high frequency in the French Massif Central (Venzac et al., 2007; Boulon et al., 2011), the Alps (Boulon et al., 2010), the Himalayas (Venzac et al., 2008) and the Bolivian Andes at $5200 \mathrm{~m}$ a.s.l., where the frequency of NPF events are among the highest in the world (Rose et al., 2015). It is important to characterize the mechanisms and gas-phase precursors to NPF specific to high altitudes because particles have a longer lifetime in this part of the atmosphere and they are in direct interaction with the environmental conditions conducive to cloud formation. The chemical species responsible for the formation of embryos and those responsible for their growth to larger sizes may be different. Therefore, in order to understand nucleation processes, it is essential to detect the embryos of particles before they are lost or grown to larger sizes. It is estimated that the first embryos of stable particles in the atmosphere have a size of $1 \mathrm{~nm}$. 
Diurnal conditions are necessary for the study of nucleation because they determine the presence of photochemical processes at the origin of nanoparticle precursor gases. High-altitude stations, however, are frequently influenced by uplifted air masses during the day, due to forced convection on mountainous slopes or natural heat convection. Therefore, it is relatively rare to meet the appropriate conditions for the study of the nucleation process taking place above the atmospheric boundary layer from ground measurement stations. Airborne measurements offer a much higher potential, not only for overcoming artifacts related to the topography of ground stations but also for evaluating the spatial (horizontal and vertical) extension of the process and reaching specific aerosol plumes (e.g., desert dust or volcanic ash in which the nucleation process could be favored). In the past, instrumentation embedded in an aircraft has been able to detect newly formed particles in a size range between 5 and $10 \mathrm{~nm}$ (Rose et al., 2015) showing that the frequency of occurrence of ultrafine particles was at its maximum in the $2000-3000 \mathrm{~m}$ altitude range. There is a need to measure nanoparticle concentrations with a controlled inlet flow rate and well-characterized low-pressure performances both for mountaintop and aircraft-based measurements.

\subsection{Technical background}

The TSI 3010 condensation particle counter (CPC) is a later version of the TSI 3760, which was designed by Keady (1988) and targeted at particle concentration monitoring in clean rooms, as can be found in the pharmaceutical and electronics industries. The TSI 3760 and other models of the same product line (TSI 3762 and TSI 3762A) are all based on the same compact and clean room compatible design. The saturator is a reservoir for the working fluid and allows several days of continuous operation. The condenser is cooled by a thermoelectric cooler (TEC) sandwiched between the condenser and a heat sink. The heat sink evacuates the heat from the hot side of the TEC and channels it to the saturator. The TEC thus cools the condenser and heats the saturator at the same time. The operating temperature $T_{\mathrm{S}}$ of the saturator is typically a few degrees above the ambient temperature. In order to prevent contamination of the ambient air (foremost specification in clean rooms), the instrument has no moving parts (neither fan nor pump). Unlike most other CPCs, the temperatures of the condenser $T_{\mathrm{C}}$ and the saturator $T_{\mathrm{S}}$ are not controlled independently. Instead, the temperature difference $\Delta T$ between the condenser and the saturator is maintained at a constant level. The thermal design was particularly well thought out and ensures that $T_{\mathrm{S}}$ is within a adequate range to saturate the sample flow with butanol vapor under a wide range of operating conditions. The optical detector block is in thermal contact with the heat sink, which keeps it warm enough to prevent the butanol vapor from condensing on the lenses.
The TSI 3760 controls the sample flow with a critical orifice and needs a vacuum pump to operate. In order to further reduce the risk of contamination, a second critical orifice is used to flush the air from the inner volume of the CPC housing. This is called the purge flow. The slight under-pressure in the housing causes any particle to be evacuated to the vacuum pump. In addition, the purge flow helps cool the electronics.

Back in 1988, all butanol-fueled CPCs had a sample flow rate of $0.3 \mathrm{~L} \mathrm{~min}^{-1}$ starting with the TSI 3020 . TSI later introduced the TSI 3022 , featuring a $1.2 \mathrm{~L} \mathrm{~min}^{-1}$ bypass flow and the same $0.3 \mathrm{~L} \mathrm{~min}^{-1}$ flow rate in the optical detector. The bypass flow, called "make-up air," reduces diffusion losses. Those $1.5 \mathrm{~L} \mathrm{~min}^{-1}$ CPCs were called "high flow", while the legacy models were called "low flow".

Keady's TSI 3760 does not have such a bypass. It operates with a sample flow rate of $1.415 \mathrm{~L} \mathrm{~min}^{-1}$ and a purge flow rate of $1.4 \mathrm{~L} \mathrm{~min}^{-1}$, making up $2.8 \mathrm{~L} \mathrm{~min}^{-1}$, about $0.1 \mathrm{ft}^{3} \mathrm{~min}^{-1}$.

The minimum size of the particles that can act as condensation nuclei depends on the supersaturation ratio of the vapor of the working fluid in the cooled condenser. The smaller the particle, the higher the supersaturation ratio required to initiate the vapor-to-droplet conversion (nucleation). The supersaturation profile in the condenser depends on the flow rate, the vapor-saturated air thermodynamic properties and condenser temperature $T_{\mathrm{C}}$. The supersaturation ratio peaks at a distance past the entrance of the condenser that depends on the parameters listed above. This is where particles activate. The remainder of the condenser beyond the maximum supersaturation point is simply used to grow the droplets to a detectable size (ca. $1 \mu \mathrm{m}$ ).

The higher the flow rate, the farther the supersaturation peak from the entrance of the condenser. Keady's design (Keady, 1988) keeps this distance short without increasing the length of the condenser, by splitting the sample flow into eight short tubes. The flow rate in each tube is $0.177 \mathrm{~L} \mathrm{~min}^{-1}$, resulting in a total sample flow rate of $1.415 \mathrm{~L} \mathrm{~min}^{-1}$. The upside of the multi-tube design is a very compact instrument. The downside, due to the small flow rate, is higher particle losses (diffusion for the smaller and transport for the bigger). Finally, with these settings, the cutoff diameter at $50 \%$ detection efficiency, denoted as $D_{P 50}$, is $11 \mathrm{~nm}$.

The optical detector features a $180^{\circ}$ layout, where the laser diode faces the photodetector. This design is tailored for "clean room" environments with ultra low particle concentrations. Nevertheless, it performs well up to concentrations of $10^{4} \mathrm{\# cm}^{-3}$.

The optical detector was made to count single particles. When a particle crosses a laser beam, light is scattered and sensed by the photodetector, which in turn generates an electrical pulse. The pulse is conditioned, then captured by a digital counter. As the flow rate is constant, it is easy to calculate the particle number concentration. At high concentrations, the probability for two particles or more to overlap as they cross the beam increases. Then, only one pulse is generated 
as several particles traverse the detector. This phenomenon, known as coincidence, results in undercounting. A correction method based on Poisson's equation (Pisani and Thomson, 1971; Gebhart, 2001) is implemented by the following equation:

$N_{\mathrm{a}}=N_{\mathrm{i}} \cdot e^{N_{\mathrm{a}} \cdot Q \cdot t}$,

where $N_{\mathrm{a}}$ is the actual concentration $\left(\# \mathrm{~cm}^{-3}\right), N_{\mathrm{i}}$ is the indicated or measured concentration $\left(\# \mathrm{~cm}^{-3}\right), Q$ is the flow rate $\left(\mathrm{cm}^{3} \mathrm{~s}^{-1}\right)$ and $t$ is the effective time each particle resides in the viewing volume. The $\mathrm{N}_{\mathrm{a}}$ in the exponent can be approximated by $N_{\mathrm{i}}$. In the first TSI $3760, Q=1.4 \mathrm{~L} \mathrm{~min}^{-1}$ and $t=0.25 \mu \mathrm{s}$, resulting in a coincidence error of only $6 \%$ at $10^{4} \mathrm{Acm}^{-3}$.

Although the TSI 3760 was designed for the clean rooms market, the good performance and affordable price helped make it popular in a wide range of applications, including atmospheric research (Ström and Ohlsson, 1998; Woo et al., 2001). Following this success, TSI introduced the now wellknown TSI 3010. This model boasts significant improvements, such as a tighter temperature control and, most importantly, the ability to drive a differential mobility analyzer (DMA, Knutson and Whitby, 1975) in a scanning mobility particle sizer (SMPS) system (Wang and Flagan, 1990). Indeed, the TSI 3010 embeds a DAC (digital-to-analog converter), the voltage of which can be set by a command sent to the RS-232 serial port interface. The TSI 3010 is based on the same concept as the TSI 3760. It has a larger liquid reservoir. But the main change is the sample flow rate, $1.0 \mathrm{~L} \mathrm{~min}^{-1}$, compared to $1.4 \mathrm{~L} \mathrm{~min}^{-1}$ in the TSI 3760 . This affects the dimensions of the tubes in the condenser, in order to maintain the same cutoff diameter $\left(D_{P 50}\right)$ around $10 \mathrm{~nm}$.

Thanks to its $10 \mathrm{~nm}$ cutoff diameter and low price compared to an ultrafine sheathed CPC, the TSI 3010 was soon widely adopted in SMPS systems, covering many fields, including laboratory experiments and field measurements (O'Dowd et al., 1998; Schröder and Ström, 1997; O'Dowd et al., 2009; O'Dowd et al., 2007). Equivalent models including TSI 3760A and TSI 3762 also became very popular for the same reasons. Bricard's work at the Puy de Dôme station (1465 $\mathrm{m}$ a.s.1.), France, leveraging the first continuous flow CPC (Bricard et al., 1972; El Golli et al., 1975), shed light on the need to measure aerosol number concentrations on mountaintops or in research aircrafts. The TSI 3010 played a key role in this field as well (Seifert et al., 2004).

The TSI 3010 is marketed with a cutoff diameter of $10 \mathrm{~nm}$, when operated at the default temperature gradient $\Delta T=T_{\mathrm{S}}-$ $T_{\mathrm{C}}=17^{\circ} \mathrm{C}$. The user can change $\Delta T$ by issuing a command on the RS-232 interface. The detection efficiency can thus be improved easily by increasing $\Delta T$ without modifying the CPC. However, $\Delta T$ is coerced to a safe range in the firmware, so as to protect the TEC and prevent homogeneous nucleation of the butanol vapor to occur. The principle of operation of the CPC is based on heterogeneous nucleation, where vapor condenses on the particles that play the role of condensation sites or seeds. In contrast, homogeneous nucleation forms droplets without a seed particle. This latter process is an unwanted side effect that must be avoided. The onset of homogeneous nucleation imposes the maximum $\Delta T$ for a given flow rate in a given saturator-condenser geometry.

Mertes et al. (1995) measured the cutoff diameter for different temperature gradients $\Delta T$ varying from 17 to $25^{\circ} \mathrm{C}$ down to $5 \mathrm{~nm}$. We note that the cutoff diameter of the TSI 3025 , a sheathed CPC, is $2.7 \mathrm{~nm}$ with a sample flow rate of only $0.3 \mathrm{~L} \mathrm{~min}^{-1}$ (Kesten et al., 1991). With a custombuilt TSI 3010-like CPC with a heating mat on the saturator, an additional TEC on the condenser and a modified EEPROM (nonvolatile memory integrated circuit), Russell et al. (1996) were able to independently reach $T_{\mathrm{S}}=38$ and $T_{\mathrm{C}}=2{ }^{\circ} \mathrm{C}$, respectively $\left(\Delta T=36^{\circ} \mathrm{C}\right)$. They measured the detection efficiency with aerosols of salt $(\mathrm{NaCl})$ and silver as small as $4.5 \mathrm{~nm}$. No homogeneous nucleation was detected with a $1 \mathrm{~L} \mathrm{~min}^{-1}$ particle-free air stream at $\Delta T=36^{\circ} \mathrm{C}$. During an intercomparison study of the size dependent detection efficiency of 26 CPCs, Wiedensohler et al. (1997) showed that for the TSI 3010 operating at $\Delta T=36^{\circ} \mathrm{C}$ and $Q=1 \mathrm{~L} \mathrm{~min}^{-1}$, the cutoff diameter of silver particles is $3.75 \mathrm{~nm}$, without homogeneous nucleation. Finally, it was found that for a given temperature gradient $\Delta T$, the detection efficiency is higher if the condenser temperature $T_{\mathrm{C}}$ is lower (Barmpounis et al., 2018).

\section{Design of the $B 3010$}

CPCs can be separated in two main categories: non-sheathed sample flow (Bricard et al., 1976; Keady, 1988) and sheathed sample flow (Stolzenburg and McMurry, 1991). The former are more robust and cheaper, while the latter boast a higher detection efficiency of sub- $10 \mathrm{~nm}$ particles and a lower probability of coincidence at high particle concentrations. Indeed, as noticed in Wiedensohler et al. (1994), the very low aerosol flow rate in sheathed CPCs, such as the TSI 3025 may lead to systematic deviations and statistical uncertainties in lowconcentration situations. The instrument described here belongs to the first category of non-sheathed CPCs.

The goal of this development, encouraged by a recent study by Kangasluoma et al. (2015) that demonstrated the possibility of detecting sub-3 $\mathrm{nm}$ particles by merely changing the temperatures in a standard TSI 3772 (successor of the TSI 3010), is to approach the performances of an ultrafine CPC (UCPC) while sticking to a simple and robust design.

As we target airborne measurements, aircraft safety rules and specific constraints made the design process somewhat more complex. Airborne requirements include the ban of external butanol fill bottles and the need for all instruments to connect to common inlets and exhaust lines in order to avoid a critical cabin pressure drop. In other words, the inner flow 
paths of the instruments are at the outside ambient pressure, while the rest of the instruments are at cabin pressure. Aside from this, the power supplies found in aircrafts can produce large voltage transients, possibly causing permanent damage to electronic devices.

In order to reduce the development time, our design reuses the saturator, condenser and optics of an original TSI 3010. Everything else was redesigned, involving 3-D CAD modeling, electronics and software design. The saturator taken from the TSI 3010 is also a reservoir that can hold more working fluid (butanol) than needed for a standard flight of 4 to $6 \mathrm{~h}$, thus eliminating the need for an external fill bottle.

The key parameters that govern the cutoff diameter of a $\mathrm{CPC}$ are the volume flow rate and the temperature gradient between the saturator and the condenser. In order to gain full control over the supersaturation process, it was necessary to control each of them separately. Indeed, the original TSI 3010 uses a thermoelectric cooler (TEC) to pump the heat out of the condenser and into the saturator, thus acting as a cooler and a heater at the same time. The temperature gradient is kept constant but without control on the condenser absolute temperature. Aside from this, the flow rate is set by a critical orifice and is not measured. The flow rate cannot be changed unless the orifice is replaced.

For our purpose, we had to break the thermal bond between the hot side of the TEC and the saturator block. The tall heat sink was replaced by a smaller one but with forced convection. The TEC was replaced by two TECs connected in series. Resistive heaters were stuck on the saturator block. In addition, in order to prevent the butanol from condensing on the optics, a heater was added on the optical block. The optical block temperature is kept above ca. $40^{\circ} \mathrm{C}$. Finally, we added the option to switch easily between the critical orifice and a small rotary vane pump to suit all use cases. The pump allows to adjust the flow rate at will and removes the need for a bulky external vacuum pump.

We measure the flow rate with a laminar flow element corrected for absolute pressure. The absolute pressure is measured by a miniature sensor connected to the optical chamber with a capillary tube. The pressure intake is centrally located, between the saturator-condenser block and the laminar flow element. The volume flow rate is calculated from the differential pressure measured by a $50 \mathrm{~Pa}$ miniature sensor across a laminar flow element and compensated for absolute pressure. The volume flow rate was calibrated with a DryCal Gilibrator bubble volume flowmeter for a number of absolute pressures. The volume flow rate is a key measurement, since it is used to calculate the particle number concentration. The concentration $C$ is calculated from the number of particle counts, $N$, accumulated during, $T_{\mathrm{S}}$, at a volume flow rate, $Q_{\mathrm{V}}$, according to Eq. (2).

$$
C=\frac{N}{Q_{\mathrm{V}} \cdot T_{\mathrm{S}}}
$$

The electronic boards of the CPC were redesigned from scratch. The power supply board was designed to operate off aircrafts' 28 V DC board with special care taken to stand reverse polarity and load dumps. The power supply can stand $\pm 80 \mathrm{~V}$ overvoltages and features overcurrent protection (current limiting). A second board is used to control the current in the TECs with fast, high-power metal-oxide semiconductor field-effect transistors (MOSFETs) in a half bridge. Finally a sensor board with an 8-bit microcontroller measures pressure, temperature, flow rate, counts the pulses from the optics and generates $300 \mathrm{kHz}$ waveforms to drive the TEC power supply MOSFETs.

The system is controlled by a credit card sized computer board powered by an ARM processor. The operating system is a custom-made Linux system, built from scratch with the Buildroot framework. The computer runs advanced software algorithms (Landau, 1993) to achieve a tight control on the flow rate $\left( \pm 0.02 \mathrm{~L} \mathrm{~min}^{-1}\right)$ and temperature $\left( \pm 0.1^{\circ} \mathrm{C}\right)$. The B3010 features a TSI-compatible serial port command set, a BNC pulse output connector, data recording capability and a $9.7 \mathrm{~cm}$ touchscreen. An Ethernet port allows remote access while the software is running, due to the multitasking nature of Linux. The software is written in C++ with the Qt open source library.

\section{Calibration bench}

\subsection{Experimental setup}

The experimental setup given in Fig. 2 is the classical setup and method used during the last few decades for the generation of sub-10 nm and detection-efficiency measurements with a high particle size resolution. It has been widely documented in the literature (Heim et al., 2010; Jiang et al., 2011; Kangasluoma et al., 2015; Hering et al., 2016; Kangasluoma et al., 2017; Barmpounis et al., 2018).

The differential mobility analyzer (DMA) used in this study is called a Herrmann-type DMA and has been described in detail in Kangasluoma et al. (2016). DMAs are operated with two flows: $Q_{\mathrm{a}}$, the aerosol (or sample) flow and $Q_{\text {s }}$, a filtered, aerosol-free sheath flow. The size resolution of a DMA is given by the ratio $Q_{\mathrm{a}} / Q_{\mathrm{s}}$. Typical DMAs are operated at $Q_{\mathrm{a}}=1-4$ and $Q_{\mathrm{s}}=5-20 \mathrm{~L} \mathrm{~min}^{-1}$. The Herrmanntype DMA used in this study is operated at $Q_{\mathrm{a}}=10$ and $Q_{\mathrm{s}}=250-1500 \mathrm{~L} \mathrm{~min}^{-1}$. The much higher $Q_{\mathrm{a}} / Q_{\mathrm{s}}$ ratio is the key parameter for selecting aerosol particles with a high resolution. A high-resolution DMA is needed because the particles used to measure the detection efficiency are in a very narrow size range. With Fig. 3, we can calculate the resolution of the DMA, defined by the full width at half maximum of the peak (FWHM) over the central size of the peak (Kangasluoma et al., 2016). The FWHM of $0.1 \mathrm{~nm}$ over the monomer size $1.47 \mathrm{~nm}$ gives a resolution of 0.07 (dimensionless number) in the conditions of the experiments. 

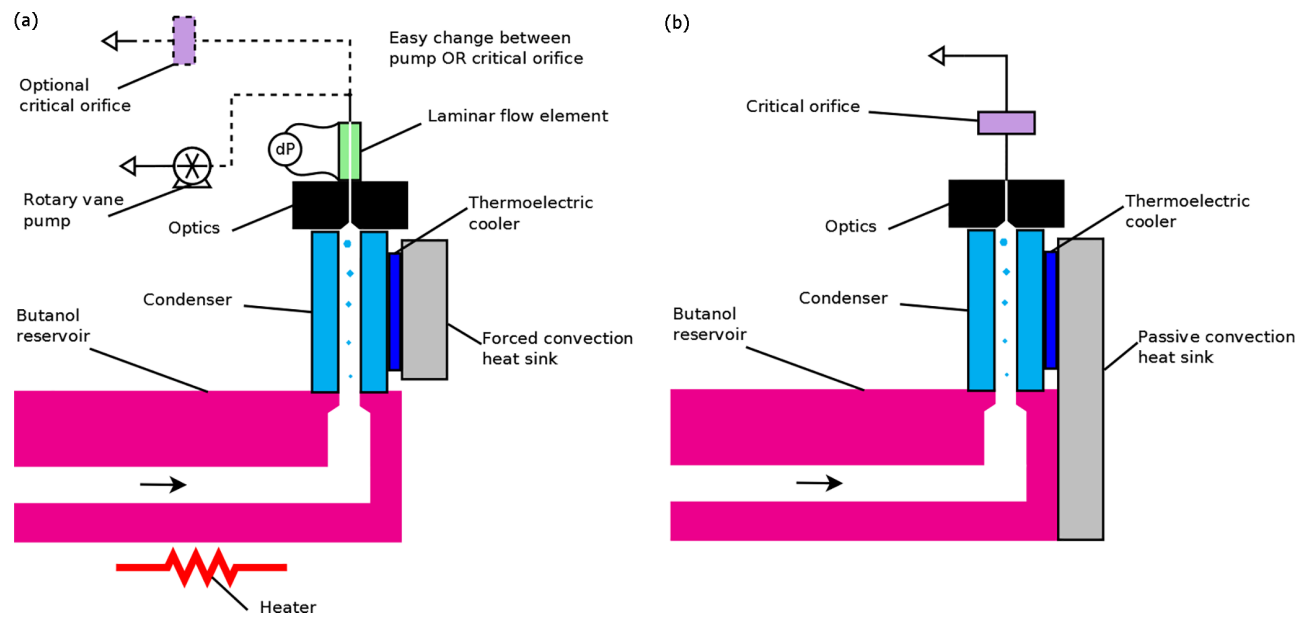

Figure 1. B3010 (a) and TSI 3010 (b) diagrams.

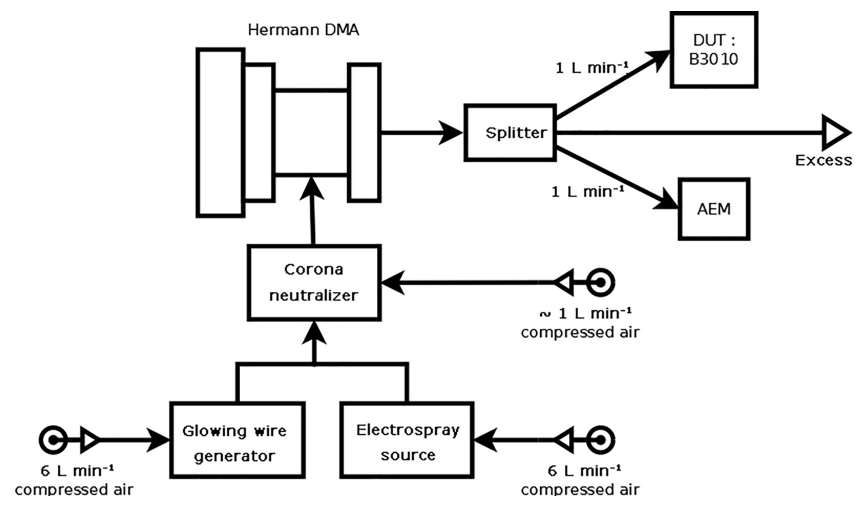

Nitrogen is used as a carrier gas for the wire generator and electrospray source to push the particles into the Herrmann DMA at a flow rate of $6 \mathrm{~L} \mathrm{~min}^{-1}$. Indeed, the transmission in the DMA is higher in sub-3 nm particles when the aerosol flow rate is higher than $5 \mathrm{~L} \mathrm{~min}^{-1}$ (Kangasluoma et al., 2016).

The monodisperse aerosol flow exiting the DMA is distributed via a three-port flow splitter to the device being tested (B3010), the Keithley 6517B reference aerosol electrometer (AEM) and an exhaust line for the excess air. Conductive soft tubes of equal lengths are used to connect the splitter to the B3010 and the AEM in order to level off the deposition losses in both lines.

The flow rate in the loop of the DMA is constant but is

Figure 2. Experimental setup.

However, this high resolution comes at a price: the small particle size range. Indeed, at such a high sheath flow rate, the voltage required for selecting particles bigger than 5-6 nm produces electric arcs in the DMA and thus sets the upper limit. Aside from this, the principle of linking the DMA voltage and actual particle size is based on the DMA voltage at which the peaks of a molecular standard of known size are resolved (Ude and Fernandez De La Mora, 2005). The relationship between voltage and size is established in the conditions of the experiment and remains valid provided the conditions do not change. Reducing the sheath flow rate would allow for selecting bigger particles, but their size would be unknown.

Two different types of aerosols are used in this study to test the response of the $\mathrm{B} 3010$ in the sub- $3 \mathrm{~nm}$ range. Mobility standard ions generated with an electrospray source for organic and metal oxides produced with a glowing wire generator for hydrophobic particles are used sequentially as the sources of polydisperse aerosols in front of the highresolution Herrmann-type DMA (Kangasluoma et al., 2016). The DMA is run in a closed loop arrangement. Both methods produce their own single-charged aerosol particles. neither measured nor known. The flow control uses the actual speed output of the high-flow blower to control the flow rate. Tetraheptylammonium bromide is used as a standard to calibrate the flow rate of the DMA at the beginning of the experiments and to check the stability of the system afterwards. Then, a different type of aerosol can be injected into the DMA because the parameters of the DMA don't change as long as the flow rates are kept constant. The calibration factor $k$, determined by calibration, is needed to relate the particle mobility $Z$ to the measured voltage $\mathrm{V}$. The factor $k$ is then given by the following expression:

$k=\frac{Z \cdot V}{Q}=Z \cdot V=c s t$,

where $k$ is constant if $Q$ is constant. $Q$ is the total flow rate in the DMA, which in our case can be approximated to the sheath flow rate. $Q$ is assumed to be constant hereafter. $Z$ is the mobility diameter and $V$ the voltage in the DMA. The mobility diameter $Z_{s}$ of the monomer $\mathrm{THA}^{+}$is selected by the DMA for a voltage $V_{\mathrm{s}} . Z_{s}=1 / 1.03 \mathrm{~cm}^{2} \mathrm{~V}^{-1} \mathrm{~s}^{-1}$ is given by Ude and Fernandez De La Mora (2005). 
Table 1. Molecular standards dissolved in ethanol

\begin{tabular}{llll}
\hline Abbr. & Formula & Name & $\begin{array}{l}\text { Soluble } \\
\text { in water }\end{array}$ \\
\hline TBAB & $\mathrm{C}_{16} \mathrm{H}_{36} \mathrm{BrN}$ & $\begin{array}{l}\text { Tetra-n-butylammonium } \\
\text { bromide }\end{array}$ & no \\
TXAB & $\mathrm{C}_{24} \mathrm{H}_{52} \mathrm{BrN}$ & $\begin{array}{l}\text { Tetrahexylammonium } \\
\text { bromide } \\
\text { Tetraheptylammonium } \\
\text { bromide }\end{array}$ & yes \\
THAB & $\mathrm{C}_{28} \mathrm{H}_{60} \mathrm{BrN}$ & no \\
\hline
\end{tabular}

As $k$ is a constant, we can write:

$k=V_{\mathrm{s}} \cdot Z_{s}=V \cdot Z$,

where $V$ is the voltage required for selecting particles of mobility $Z$ with the DMA.

Equation (4) is then used to transform the horizontal axis of the measured distribution concentration versus voltage given by the scanning ramp of the inner electrode of the DMA to the distribution concentration mobility.

The mobility diameter of the measured mobility distribution is then converted to mobility diameter using the StokesCunningham equation (Friedlander, 2000):

$$
\left\{\begin{array}{c}
Z_{S_{c}}=n \cdot e \cdot \frac{1+K n \cdot\left(A+B \cdot e^{\frac{-C}{K n}}\right)}{3 \cdot p \cdot \mu \cdot d_{z}} \\
K n=2 \frac{\lambda_{\mathrm{g}}}{d_{z}} \quad \lambda_{g}=\frac{\mu}{\rho_{\mathrm{g}}} \sqrt{\frac{\pi \cdot M_{g}}{2 \cdot R \cdot T}},
\end{array}\right.
$$

where $d_{z}$ (noted $d$ in the rest of the paper) is the mobility diameter, $\mu$ is the dynamic viscosity, $n$ is the number of elementary charges e born by the ion or particle, $K n$ is the Knudsen number, $\lambda_{\mathrm{g}}$ is the mean free path of the molecules of the carrier gas, $\rho_{\mathrm{g}}$ its density and $T$ its temperature. The constants $A, B$ and $C$ are taken from Friedlander (2000).

\subsection{Molecular standards}

We use the molecular standards listed in Table 1 to generate particles in the nanometer range with the electrospray source. The standards are dissolved in ethanol at a concentration of $1 \mathrm{mmol} \mathrm{L}^{-1}$, according to the method described in Ude and Fernandez De La Mora (2005). The dissolved compounds can qualify as standards because (1) they produce individual molecules, the size of which is stable and known and (2) because the DMA resolution is high enough to separate the peaks of the individual molecules from each other.

The monomer and dimer of the molecular standards are so small that they can only bear a single electric charge. But most particles larger than about $1.8 \mathrm{~nm}$ carry multiple charges and hence generate a much higher current in the electrometer than if they all had borne a single charge. Thus, the electrometer overestimates the particle number concentration by at least an order of magnitude. As a result, the CPC detection efficiency is underestimated for these particles.

Traditionally, molecular standards have mostly been used up to about $2 \mathrm{~nm}$. But in order to measure the ability of the B3010 to detect molecular standard ions at sizes larger than $2 \mathrm{~nm}$, we insert a small corona discharge device, operated at a DC voltage of about $3 \mathrm{kV}$. The sign of the voltage is the opposite of that of the charge of the particles selected in the DMA. The benefit of the corona discharge can be seen in Fig. 3.

\subsection{Glowing wire generator}

In the second set of experiments, we use hydrophobic oxide particles produced by a glowing wire generator, as described in Peineke et al. (2006) and Kangasluoma et al. (2013). The metal wire is heated resistively with a DC current of several amps. When it reaches a high enough temperature, the wire starts to glow like the filament of a light bulb. It is installed in a stainless steel ISO KF NW40-flanged cross: the gas inlet faces the gas outlet,and a view port faces the wire mount. The wire is flushed with a $10 \mathrm{~L} \mathrm{~min}^{-1}$ nitrogen stream to carry the produced material towards the DMA and to keep the temperature of the wire well bellow the melting point. The wire is the hottest point of the generator. The volatile material condenses by homogeneous nucleation as soon as it drifts from the hot wire surface to form self-charged positive and negative particles from a few nanometers to a few tens of nanometers.

In this study, we use a tungsten oxide alloy (WOX) $\varnothing 1.0 \times$ $100 \mathrm{~mm}$ wire.

\section{Experimental results and discussion}

\subsection{Laboratory calibration}

The detection efficiency is the most representative characteristic of a CPC and is what we focus on in this section. The detection efficiency $\eta$ of the CPC is defined as the ratio between the particle concentration measured by the CPC, $N_{\mathrm{CPC}}$ to the particle concentration given by the aerosol electrometer, $N_{\mathrm{AE}}$, for different diameters, signs or $\Delta T$, according to Eq. (6).

$\eta=\frac{N_{\mathrm{CPC}}}{N_{\mathrm{AE}}}$

We measured the detection efficiency of the B3010 for three molecular standards, including positively and negatively charged particles for a $\Delta T$ of $46^{\circ} \mathrm{C}$ and $T_{\mathrm{C}}$ of $10^{\circ} \mathrm{C}$ (Fig. 4). The sign of the charge of the particles depends on the sign of the voltage applied to the electrospray generator. The B3010 exhibits the same cutoff diameter of about $3 \mathrm{~nm}$ for all three standards, soluble or not, demonstrating the rel- 


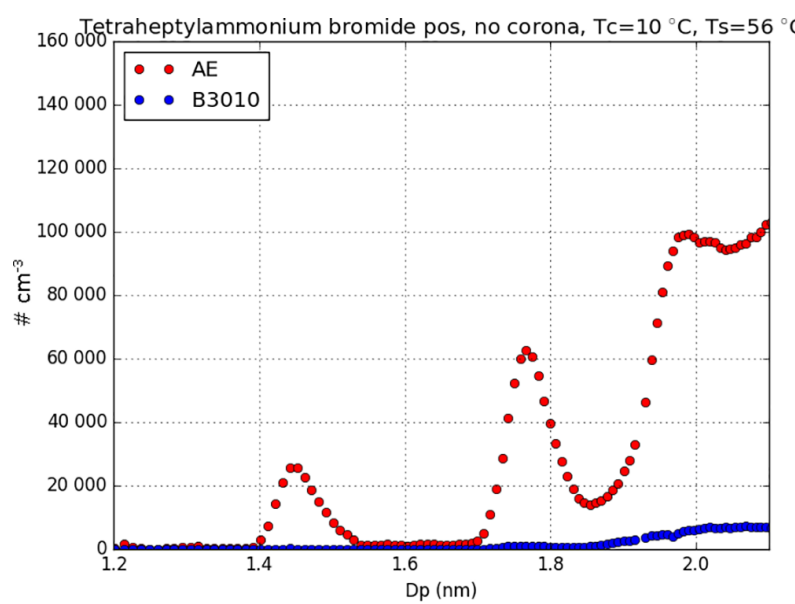

(a)

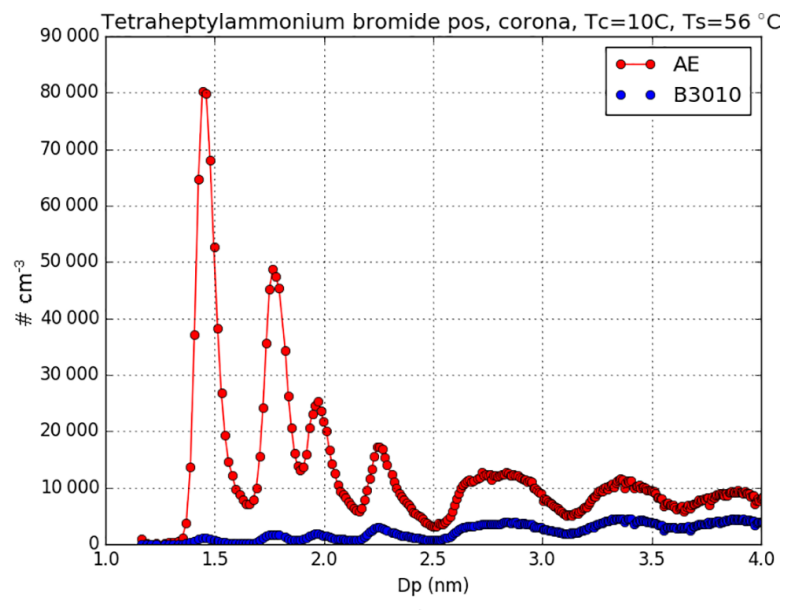

(b)

Figure 3. Effect of the corona discharge. When the corona discharge is off (a), the signal of the aerosol electrometer (AE) rises sharply above $2 \mathrm{~nm}$. When the corona discharge is on (b), the DMA can resolve up to the fourth peak.

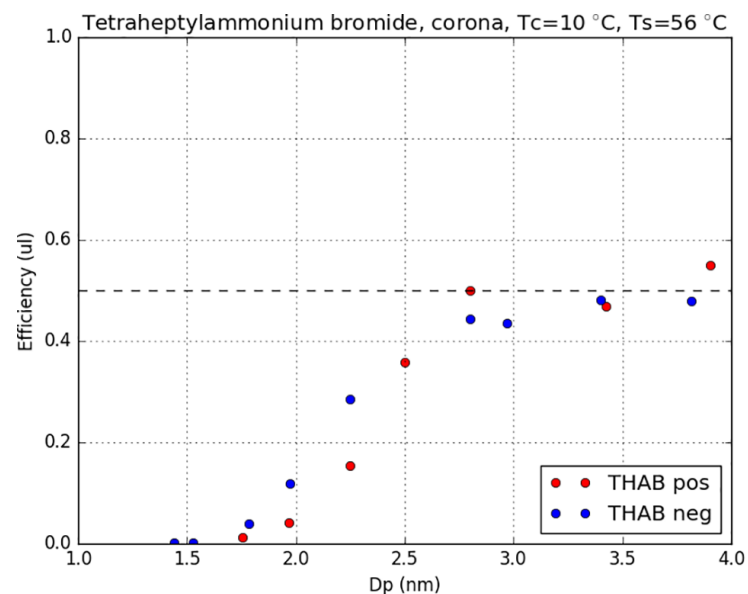

(a) THAB

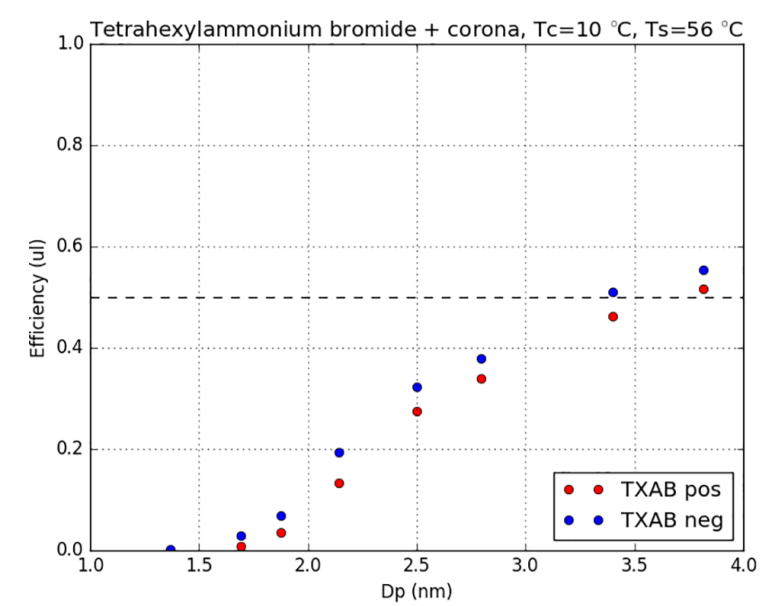

(c) TXAB

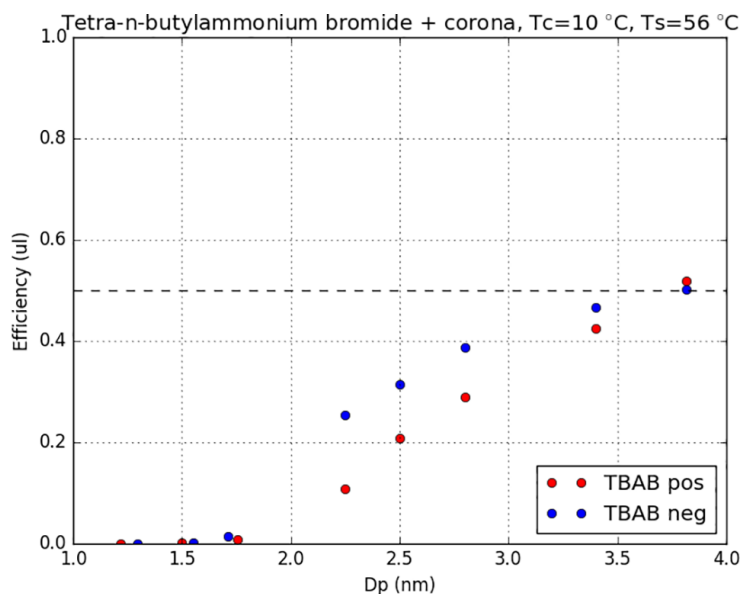

(b) TBAB

Figure 4. Detection efficiency curves measured for various laboratory-generated aerosols. 


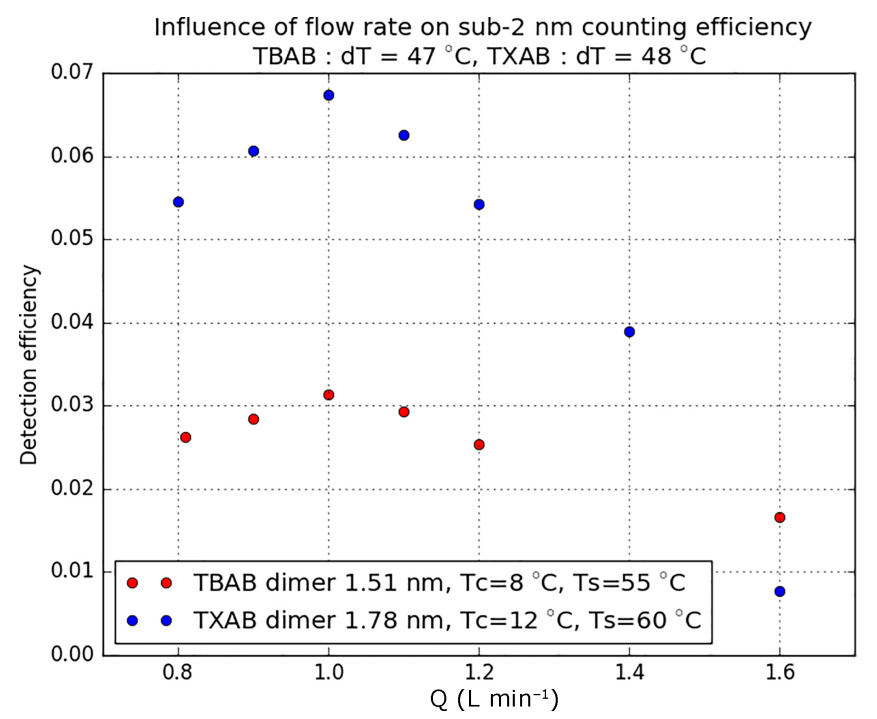

Figure 5. B3010 detection efficiency as a function of flow rate in the sub- $2 \mathrm{~nm}$ range.

ative insensitivity of butanol to the chemical composition of particles (Kangasluoma et al., 2014).

However, we can see in Fig. 4 that the detection efficiency is higher for negative particles, compared to positive particles. This phenomenon is known as "sign preference" and has been observed by a number of studies before this one. More than a century ago, Wilson $(1897,1899)$ reported that more fog is formed in an expansion chamber when negative ions are present compared to positive ions. Also, more fog forms in the presence of bipolar ions compared to no ions at all. Wilson is cited by McMurry (2000). More recent studies (Winkler et al., 2008; Kangasluoma et al., 2013) reported the same thing. This observation is thus in accordance with previous studies.

The efficiency should only increase with increasing particle diameter. However, the curves in Fig. 4 reach a plateau. Despite the corona discharge, the efficiency is clearly underestimated for particles bigger than about 3 to $4 \mathrm{~nm}$ for the reasons detailed earlier.

Figure 5 illustrates the dependence of the B3010 detection efficiency on the sample flow rate for two different $\Delta T$. We observe that the efficiency does not vary monotonically with respect to the flow rate. As reported by Kuang et al. (2012) and Kangasluoma et al. (2015), this is the evidence of a competition between diffusion losses and the time spent in the supersaturated flow. At low flow rates, the diffusion losses are higher, but the particles have more time to activate and grow to a detectable size. At higher flow rates, the diffusion losses are smaller, but the residence time is too short for the droplets to grow to a detectable size. Indeed, when the flow rate increases, the saturation profile develops further down the condenser tubes, thus contributing to decrease the residence time of the particles in supersaturated conditions. The

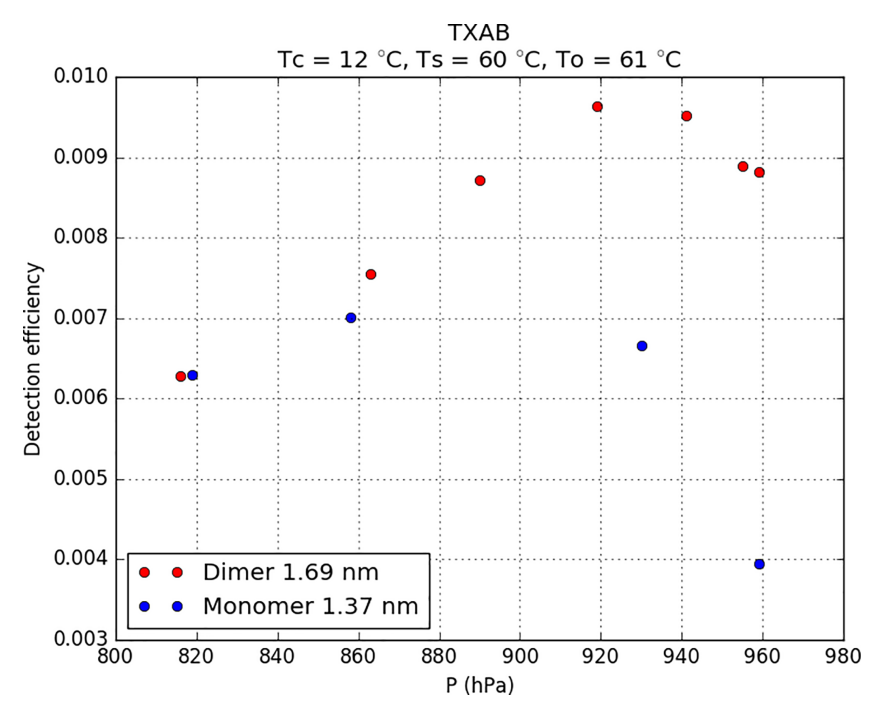

Figure 6. B3010 detection efficiency as a function of inlet pressure for two fixed-sized standards: TXAB monomer and dimer.

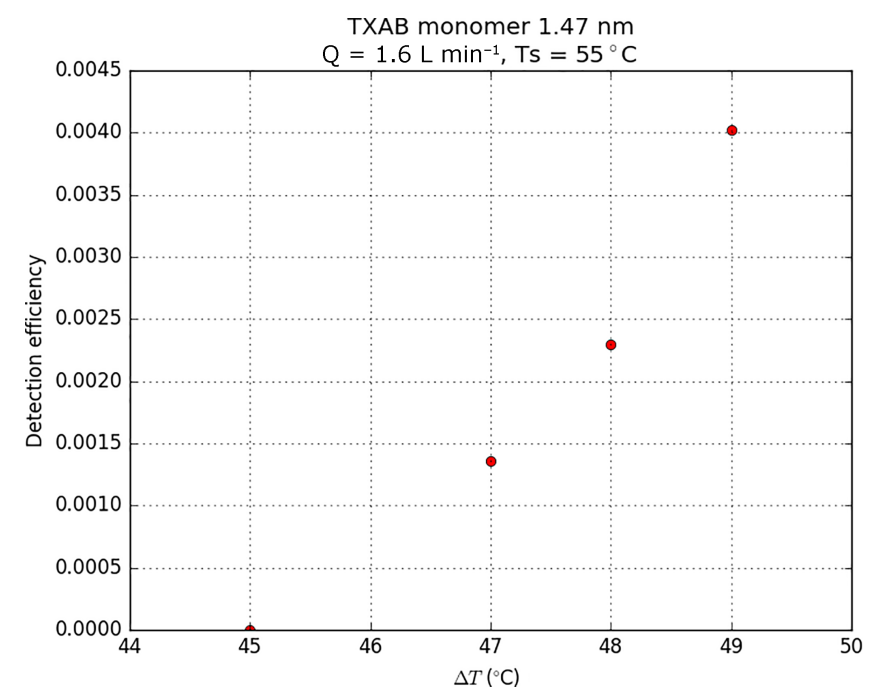

Figure 7. B3010 detection efficiency as a function of temperature gradient for TXAB monomer.

detection efficiency peaks at $1 \mathrm{~L} \mathrm{~min}-1$, which is exactly the nominal flow rate of the TSI 3010 . We can notice here that increasing $\Delta T$ from 17 to $47-48^{\circ} \mathrm{C}$ does not shift the optimum flow rate value.

In order to study the effect of pressure on the detection efficiency, we inserted a pinched tube section in the setup of Fig. 2, between the DMA and the flow splitter. We favor a pinched tube over a needle valve since it features lower particle losses. By reducing this variable tube section, we are able to reduce the pressure in both the aerosol electrometer and the B3010. A pinched tube has a greater penetration efficiency than a needle valve. The effect of the inlet pressure on the B3010 detection efficiency is illustrated in Fig. 6. 


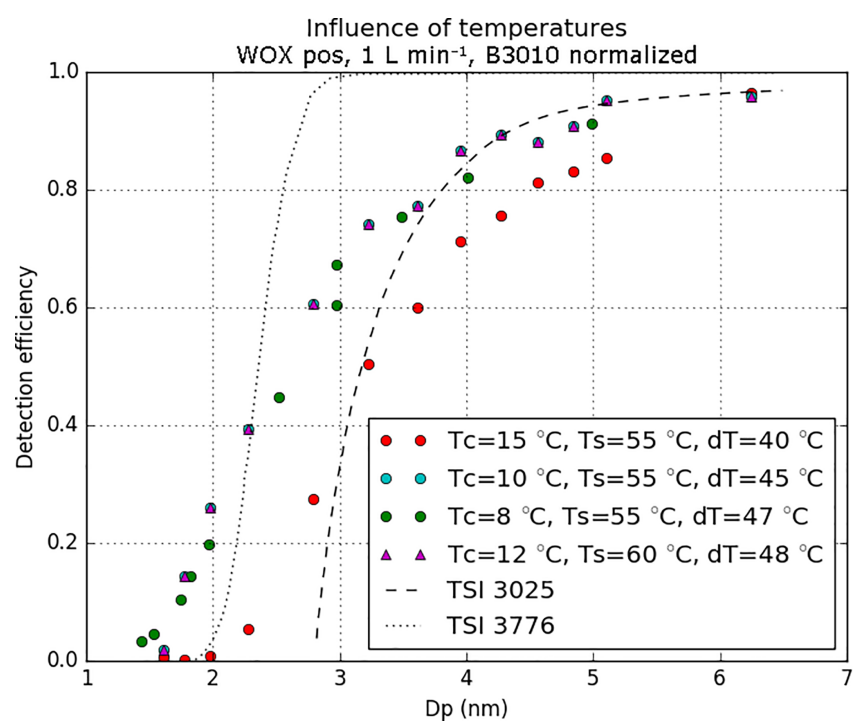

Figure 8. Influence of temperatures on detection efficiency of tungsten oxide particles. The black lines are the typical curves of ultrafine CPCs TSI $3025\left(D_{P 50}=3.0 \mathrm{~nm}\right)$ and TSI $3776\left(D_{P 50}=\right.$ $2.5 \mathrm{~nm})$.

As the pressure decreases in the condenser, the mean free path of the particles increases as well. The probability for them to hit the walls is greater. This leads to an increase in diffusion losses, especially for the smaller, more mobile particles.

Figure 8 shows how the detection efficiency increases when the temperature gradient $\Delta T=T_{\mathrm{s}}-T_{\mathrm{c}}$ increases. For a $\Delta T$ of $40^{\circ} \mathrm{C}$, the cutoff diameter is $3 \mathrm{~nm}$, while for a $\Delta T$ of $45^{\circ} \mathrm{C}$ the cutoff diameter is $2.5 \mathrm{~nm}$. Homogeneous nucleation was never observed under our experimental conditions. We also observe, as already reported by Barmpounis et al. (2018), that the amplitude of the temperature gradient not only impacts the detection efficiency but also the shift of this "temperature window" in the temperature domain. The B3010 thus has the same detection efficiency if $\Delta T=48^{\circ} \mathrm{C}$ at $T_{\mathrm{c}}=12{ }^{\circ} \mathrm{C}$ or if $\Delta T=47^{\circ} \mathrm{C}$ at $T_{\mathrm{c}}=8^{\circ} \mathrm{C}$. The efficiency curves of two ultrafine $\mathrm{CPCs}$, taken from the product specification sheets, are plotted alongside the B3010 calibration data in Fig. 8 for comparison.

The increase in performance achieved in this development is shown in Fig. 9. The B3010, a "boosted" version of the TSI 3010 competes almost with ultrafine CPCs. Again, as the flow path was not optimized for sub- $10 \mathrm{~nm}$ particles, the curve is not as steep as those of ultrafine CPCs.

The cutoff diameter is defined as the particle size at $50 \%$ efficiency and is abbreviated $D_{P 50}$. We applied the exponential fit of Eq. (7) to the data in Fig. 9.

$\eta=y_{0}-e^{\frac{x_{0}-x}{k}}$, where $\eta$ is the detection efficiency; $x$ is the particle size; and $y_{0}, x_{0}$, and $k$ are the coefficients of the fit. This type of fit is commonly used in the community (Wiedensohler et al., 1997). We can calculate $D_{P 50}$ by evaluating the inverse fit function for a detection efficiency $\eta=0.5$. The associated error is given by Eq. (8), where $R$ is the resolution of the DMA calculated in Sect. 3.1. The 0.5 factor comes from the fact that $R$ is calculated from FWHM. We can thus tell that $D_{P 50}=2.5 \pm 0.1 \mathrm{~nm}$.

$\epsilon=\frac{D_{P 50} \cdot R}{2}$

The response time of our CPC was measured in Enroth et al. (2018). It was found that the B3010 has a response time similar to that of the TSI 3010 , i.e., about $2.3 \mathrm{~s}$. This is not surprising, since both models share the same geometry.

\subsection{Ambient measurements}

Finally, we had the B3010 measure ambient air in a suburban location close to Clermont-Ferrand (France), alongside a TSI 3025 and a TSI 3010 for $3 \mathrm{~d}$. The settings were $T_{\mathrm{c}}=10^{\circ} \mathrm{C}, T_{\mathrm{s}}=56^{\circ} \mathrm{C}$ and $Q=1.0 \mathrm{~L} \mathrm{~min}^{-1}$. The $\mathrm{B} 3010$ is corrected for coincidence with Eq. (1).

The maximum particle counting rate is limited by the coincidence in the optics. The higher the number of particles flowing through the optics, the higher the probability of coincidence. In the TSI 3025 , only a fraction of the intake air is sampled, the rest being used to make filtered sheath air. Thus, this dilution reduces the number of particles flowing through the optics and hence the coincidence phenomenon. According to the manual, it can count up to $10^{5} \mathrm{\#} \mathrm{cm}^{-3}$ without coincidence. On the other hand, in the TSI 3010 the sample air is not diluted and the maximum measurable concentration without coincidence is $10^{4} \mathrm{\#} \mathrm{cm}^{-3}$. As the B3010 has the same design and optics as the TSI 3010, we expect a similar concentration range. Figure 10a focuses on a high-concentration episode, when the concentration peaks above $10^{4} \# \mathrm{~cm}^{-3}$. The B3010 curve crosses the

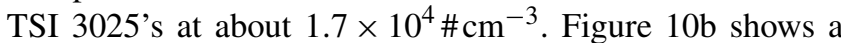
low-concentration episode, when the concentration was below $10^{4} \mathrm{Am}^{-3}$ at all times. In these conditions where the comparison is fairer, the concentration of the B3010 is significantly higher than that of the TSI 3025, which is in accordance with Fig. 9a.

In Fig. 11, we show an example application of the B3010 to retrieve the size distribution at the lower particle diameters, like in Kangasluoma et al. (2014). We plot three particle size bins, obtained by the difference of the concentrations $N$ reported by CPCs pairs.

- Small - B3010 minus TSI 3025, $2.5<N<3.0 \mathrm{~nm}$

- Medium - TSI 3025 minus TSI 3010, $3.0<N<10 \mathrm{~nm}$

- Large - TSI 3010, $N>10 \mathrm{~nm}$ 


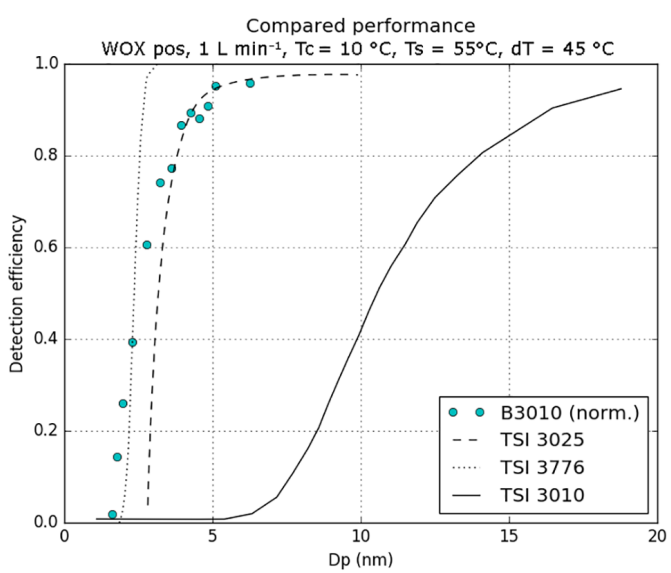

(a) B3010 vs. commercial models

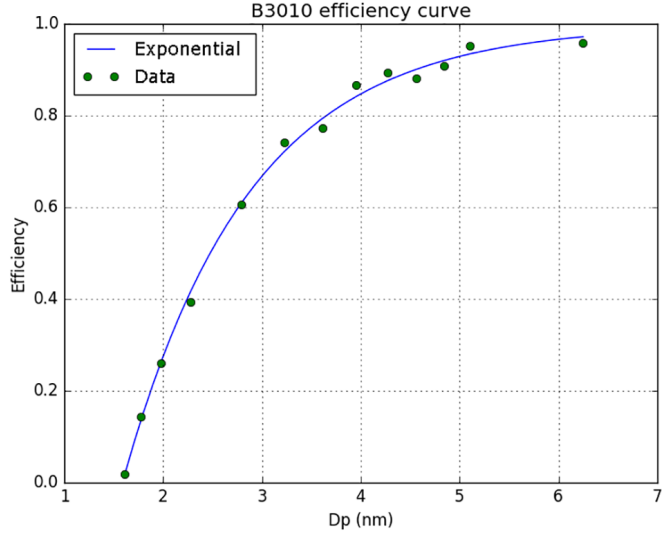

(b) Exponential fit

Figure 9. Gain in performance. Tungsten oxide particles. The data from TSI CPCs are taken from product brochures (a). The B3010 efficiency is fit with an exponential curve (b) to retrieve the cutoff diameter. The data from the B3010 are normalized.
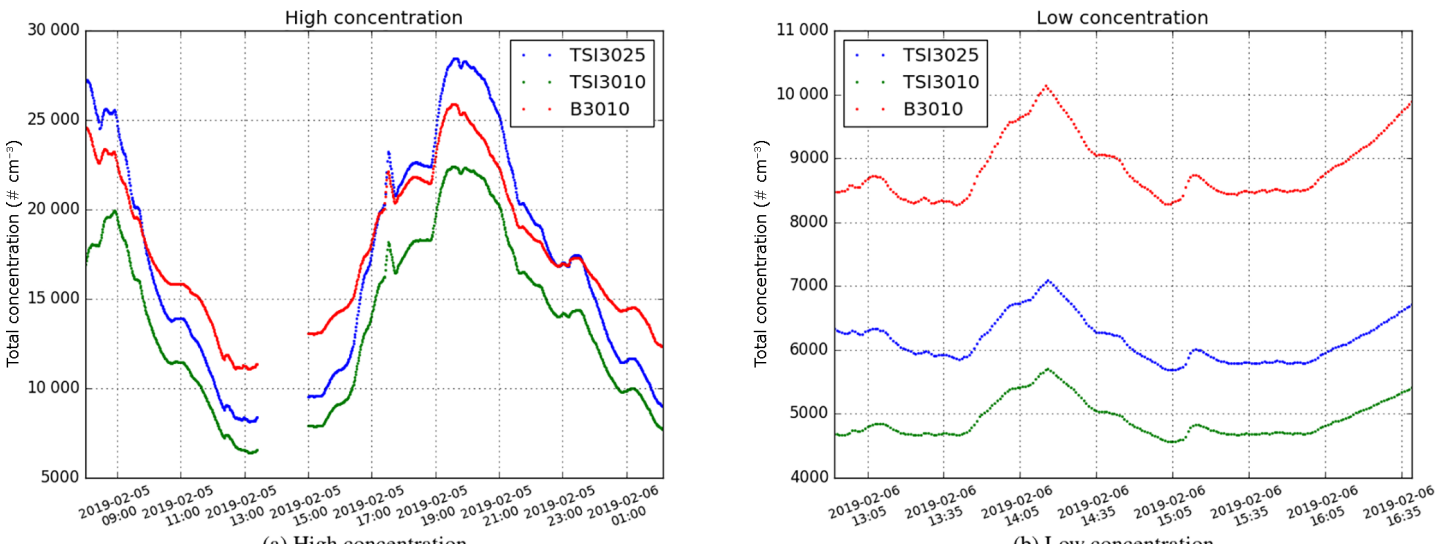

(a) High concentration

(b) Low concentration

Figure 10. Comparing B3010 with TSI 3025 and TSI 3010 during a high-concentration episode (a) and a low-concentration episode (b).

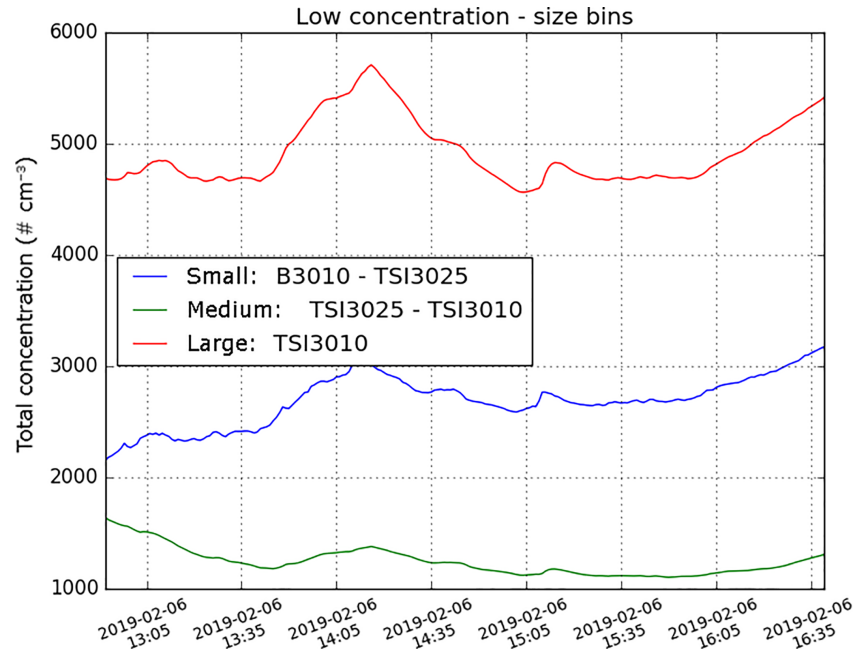

Figure 11. The B3010 in a CPC battery.
In this example, one can see that particles in the range 2.5 $3.0 \mathrm{~nm}$ account for about a third of the total particle concentration.

\section{Conclusions}

In this project, we demonstrate that a CPC with a simple, proven design such as the TSI 3010's can be slightly modified to bring the detection efficiency close to that of ultrafine, sheathed CPCs. Both laboratory and ambient measurements confirm this result. However, as emphasized in the ambient measurements section, the maximum measurable concentration is definitely limited by the design of the flow path and the optics.

In light of the results presented here, a few guidelines for CPC designers and users can be drawn. Still today, designers could reasonably imagine non-sheathed, yet performing CPC geometries, as long as the total concentration in the targeted application is not too high. Aside from this, owners 
of non-sheathed CPCs can dramatically reduce the cutoff diameter of their devices by simply adjusting the saturator and condenser temperatures. This simple tweak, when allowed by commercial CPC firmware, can potentially help save the extra cost of an ultrafine CPC.

Data availability. Data are available upon request.

Author contributions. DP wrote the first draft and ran the ambient measurements. MA provided the laboratory calibration facility. DP, MA and KS participated in laboratory tests, data analysis and editing of the paper.

Competing interests. The authors declare that they have no conflict of interest.

Acknowledgements. This work was funded by the ClerVolc project - Program 1 "Detection and characterization of volcanic plumes and ash clouds" funded by the French government's "Laboratory of Excellence" initiative.

Review statement. This paper was edited by Szymon Malinowski and reviewed by four anonymous referees.

\section{References}

Barmpounis, K., Ranjithkumar, A., Schmidt, A.-O., Attoui, M., and Biskos, G.: Enhancing the detection efficiency of condensation particle counters for sub-2 nm particles, J. Aerosol Sci., 117, 44 53, https://doi.org/10.1016/j.jaerosci.2017.12.005, 2018.

Boulon, J., Sellegri, K., Venzac, H., Picard, D., Weingartner, E., Wehrle, G., Collaud Coen, M., Bütikofer, R., Flückiger, E., Baltensperger, U., and Laj, P.: New particle formation and ultrafine charged aerosol climatology at a high altitude site in the Alps (Jungfraujoch, $3580 \mathrm{~m}$ a.s.l., Switzerland), Atmos. Chem. Phys., 10, 9333-9349, https://doi.org/10.5194/acp-109333-2010, 2010.

Boulon, J., Sellegri, K., Hervo, M., Picard, D., Pichon, J.-M., Fréville, P., and Laj, P.: Investigation of nucleation events vertical extent: a long term study at two different altitude sites, Atmos. Chem. Phys., 11, 5625-5639, https://doi.org/10.5194/acp11-5625-2011, 2011

Bricard, J., Cazes, P., Reiss, P., and Turpin, P.-Y.: Contribution à l'étude de l'aérosol atmosphérique dans le domaine submicronique à l'aide de méthodes photoélectriques, Academie des Sciences Paris Comptes Rendus Serie B Sciences Physiques, 275, 263-266, 1972.

Bricard, J., Delattre, P., Madelaine, G., and Pourprix, M.: Detection of ultra-fine particles by means of a continuous flux condensation nuclei counter, Academic Press, 1976.
El Golli, S., Madelaine, G., Turpin, P., and Bricard, J.: Recent advances in photoelectric aerosol measurements, Water Air Soil Pollut., 5, 11-38, 1975.

Enroth, J., Kangasluoma, J., Korhonen, F., Hering, S., Picard, D., Lewis, G., Attoui, M., and Petäjä, T.: On the time response determination of condensation particle counters, Aerosol Sci. Tech., 52, 1521-7388, https://doi.org/10.1080/02786826.2018.1460458, 2018.

Friedlander, S. K.: Smoke, Dust, and Haze, Oxford University Press, 2nd edition edn., available at: http://www.oupcanada.com/ catalog/9780195129991.html (last access: 3 September 2018), 2000.

Gebhart, J.: Optical direct-reading techniques: light intensity systems, Aerosol Measurement, 419-454, 2001.

Heim, M., Attoui, M., and Kasper, G.: The efficiency of diffusional particle collection onto wire grids in the mobility equivalent size range of 1.2-8 nm, J. Aerosol Sci., 41, 207-222, https://doi.org/10.1016/j.jaerosci.2009.10.002, 2010.

Hering, S. V., Lewis, G. S., Spielman, S. R., Eiguren-Fernandez, A., Kreisberg, N. M., Kuang, C., and Attoui, M.: Detection near 1-nm with a Laminar-Flow, Water-Based Condensation Particle Counter, Aerosol Science Tech., 51, 354-362, https://doi.org/10.1080/02786826.2016.1262531, 2016.

Jiang, J., Attoui, M., Heim, M., Brunelli, N. A., McMurry, P., Kasper, G., Flagan, Richard C.and Giaspis, K., and Mouret, G.: Transfer Functions and Penetrations of Five Differential Mobility Analyzers for Sub-2 nm Particle Classification, Aerosol Sci. Tech., 45, 480-492, https://doi.org/10.1080/02786826.2010.546819, 2011.

Kangasluoma, J., Junninen, H., Lehtipalo, K., Mikkilä, J., Vanhanen, J., Attoui, M., Sipilä, M., Worsnop, D., Kulmala, M., and Petäjä, T.: Remarks on Ion Generation for CPC Detection Efficiency Studies in Sub-3-nm Size Range, Aerosol Sci. Tech., 47, 556-563, https://doi.org/10.1080/02786826.2013.773393, 2013.

Kangasluoma, J., Kuang, C., Wimmer, D., Rissanen, M. P., Lehtipalo, K., Ehn, M., Worsnop, D. R., Wang, J., Kulmala, M., and Petäjä, T.: Sub-3 nm particle size and composition dependent response of a nano-CPC battery, Atmos. Meas. Tech., 7, 689-700, https://doi.org/10.5194/amt-7-689-2014, 2014.

Kangasluoma, J., Ahonen, L., ATTOUI, M., Vuollekoski, H., Kulmala, M., and Petäjä, T.: Sub-3 nm particle detection with commercial TSI 3772 and Airmodus A20 fine condensation particle counters, Aerosol Sci. Tech., 49, 674-681, https://doi.org/10.1080/02786826.2015.1058481, 2015.

Kangasluoma, J., Attoui, M., Korhonen, F., Ahonen, L., Siivola, E., and Petäjäa, T.: Characterization of a Herrmann-type highresolution differential mobility analyzer, Aerosol Sci. Tech., 50, 222 229, https://doi.org/10.1080/02786826.2016.1142065, 2016.

Kangasluoma, J., Hering, S., Picard, D., Lewis, G., Enroth, J., Korhonen, F., Kulmala, M., Sellegri, K., Attoui, M., and Petäjä, T.: Characterization of three new condensation particle counters for sub-3 nm particle detection during the Helsinki CPC workshop: the ADI versatile water CPC, TSI 3777 nano enhancer and boosted TSI 3010, Atmos. Meas. Tech., 10, 2271-2281, https://doi.org/10.5194/amt-10-2271-2017, 2017.

Keady, P. B.: Condensation Nucleus Counter US Patent US4790650A, 1988.

Kesten, J., Reineking, A., and Porstendörfer, J.: Calibration of a TSI Model 3025 Ultrafine Condensa- 
tion Particle Counter, Aerosol Sci. Tech., 15, 107-111, https://doi.org/10.1080/02786829108959517, 1991.

Knutson, E. and Whitby, K.: Aerosol classification by electric mobility: apparatus, theory, and applications, J. Aerosol Sci., 6, 443-451, https://doi.org/10.1016/0021-8502(75)90060-9, 1975.

Kuang, C., Chen, M., McMurry, P. H., and Wang, J.: Modification of Laminar Flow Ultrafine Condensation Particle Counters for the Enhanced Detection of $1 \mathrm{~nm}$ Condensation Nuclei, Aerosol Sci. Tech., 46, 309-315, https://doi.org/10.1080/02786826.2011.626815, 2012.

Kulmala, M., Vehkamäki, H., Petäjä, T., Dal Maso, M., Lauri, A., Kerminen, V.-M., Birmili, W., and McMurry, P.: Formation and growth rates of ultrafine atmospheric particles: a review of observations, Aerosol Sci., 35, 143-176, https://doi.org/10.1016/j.jaerosci.2003.10.003, 2004.

Landau, I. D.: Identification et commande des systèmes, Hermès Science Publications, 2nd edition edn., 1993.

McMurry, P. H.: The History of Condensation Nucleus Counters, Aerosol Sci. Tech., 33, 297-322, https://doi.org/10.1080/02786820050121512, 2000.

Mertes, S., Schröder, F., and Wiedensohler, A.: The Particle Detection Efficiency Curve of the TSI3010 CPC as a Function of the Temperature Difference between Saturator and Condenser, Aerosol Sci. Tech., 23, 257-261, 1995.

O’Dowd, C. D., Geever, M., Hill, M. K., Smith, M. H., and Jennings, S. G.: New particle formation: Nucleation rates and spatial scales in the clean marine coastal environment, Geophys. Res. Lett., 25, 1661-1664, https://doi.org/10.1029/98GL01005, 1998.

O’Dowd, C. D., Yoon, Y. J., Junkerman, W., Aalto, P., Kulmala, M., Lihavainen, H., and Viisanen, Y.: Airborne measurements of nucleation mode particles I: coastal nucleation and growth rates, Atmos. Chem. Phys., 7, 1491-1501, https://doi.org/10.5194/acp7-1491-2007, 2007.

O’Dowd, C. D., Yoon, Y. J., Junkermann, W., Aalto, P., Kulmala, M., Lihavainen, H., and Viisanen, Y.: Airborne measurements of nucleation mode particles II: boreal forest nucleation events, Atmos. Chem. Phys., 9, 937-944, https://doi.org/10.5194/acp-9937-2009, 2009.

Peineke, C., Attoui, M., and Schmitt-Ott, A.: Using a glowing wire generator for production of charged, uniformly sized nanoparticles at high concentrations, J. Aerosol Sci., 37, 1651-1661, https://doi.org/10.1016/j.jaerosci.2006.06.006, 2006.

Pisani, J. F. and Thomson, G. H.: Coincidence errors in automatic particle counters, J. Phys., 4, 359-361, https://doi.org/10.1088/0022-3735/4/5/006, 1971.

Rose, C., Sellegri, K., Freney, E., Dupuy, R., Colomb, A., Pichon, J.-M., Ribeiro, M., Bourianne, T., Burnet, F., and Schwarzenboeck, A.: Airborne measurements of new particle formation in the free troposphere above the Mediterranean Sea during the HYMEX campaign, Atmos. Chem. Phys., 15, 10203-10218, https://doi.org/10.5194/acp-15-10203-2015, 2015.

Russell, L. M., Zhang, S.-H., Flagan, R. C., Seinfeld, J. H., Stolzenburg, M. R., and Caldow, R.: Radially Classified Aerosol Detector for Aircraft-Based Submicron Aerosol Measurements, J. Atmos. Ocean. Tech., 13, 598-609, https://doi.org/10.1175/15200426(1996)013<0598:RCADFA>2.0.CO;2, 1996.

Schröder, F. and Ström, J.: Aircraft measurements of sub micrometer aerosol particles $(>7 \mathrm{~nm})$ in the midlatitude free tro- posphere and tropopause region, Atmos. Res., 44, 333-356, https://doi.org/10.1016/S0169-8095(96)00034-8, 1997.

Seifert, M., Tiede, R., Schnaiter, M., Linke, C., Möhler, O., Schurath, U., and Ström, J.: Operation and performance of a differential mobility particle sizer and a TSI 3010 condensation particle counter at stratospheric temperatures and pressures, J. Aerosol Sci., 35, 981-993, https://doi.org/10.1016/j.jaerosci.2004.03.002, 2004.

Spracklen, D. V., Carslaw, K. S., Kulmala, M., Kerminen, V.-M., Mann, G. W., and Sihto, S.-L.: The contribution of boundary layer nucleation events to total particle concentrations on regional and global scales, Atmos. Chem. Phys., 6, 5631-5648, https://doi.org/10.5194/acp-6-5631-2006, 2006.

Stolzenburg, M. and McMurry, P.: An Ultrafine Aerosol Condensation Nucleus Counter, Aerosol Sci. Tech., 14, 48-65, 1991.

Ström, J. and Ohlsson, S.: In situ measurements of enhanced crystal number densities in cirrus clouds caused by aircraft exhaust, J. Geophys. Res.-Atmos., 103, 11355-11361, https://doi.org/10.1029/98JD00807, 1998.

Ude, S. and Fernandez De La Mora, J.: Molecular monodisperse mobility and mass standards from electrosprays of tetra-alkyl ammonium halides, J. Aerosol Sci., 36, 1224-1237, 2005.

Venzac, H., Sellegri, K., and Laj, P.: Nucleation events detected at the high altitude site of the Puy de Dôme Research Station, France, Boreal Environ. Res., 12, 345-359, 2007.

Venzac, H., Sellegri, K., Laj, P., Villani, P., Bonasoni, P., Marinoni, A., Cristofanelli, P., Calzolari, F., Fuzzi, S., Decesari, S., Facchini, M.-C., Vuillermoz, E., and Verza, G. P.: High Frequency New Particle Formation in the Himalayas, P. Natl. Acad. Sci. USA, 105, 15666-15671, https://doi.org/10.1073/pnas.0801355105, 2008.

Wang, S. C. and Flagan, R. C.: Scanning Electrical Mobility Spectrometer, Aerosol Sci. Tech., 13, 230-240, https://doi.org/10.1080/02786829008959441, 1990.

Wiedensohler, A., Aalto, P., Heintzenberg, J., and McMurry, P. H.: Intercomparison of Four Methods to Determine Size Distributions of Low-Concentration (ca. $100 \quad 1 / \mathrm{cm}$ ), Ultrafine Aerosols $(3<\mathrm{Dp}<10 \mathrm{~nm})$ with Illustrative Data from the Arctic, Aerosol Sci. Tech., 2, 95-109, https://doi.org/10.1080/02786829408959700, 1994.

Wiedensohler, A., Orsini, D., Covert, D. S., Coffmann, D., Cantrell, W., Havlicek, M., Brechtel, F. J., Russell, L. M., Weber, R. J., Gras, J., Hudson, J. G., and Litchy, M.: Intercomparison Study of the Size-Dependent Counting Efficiency of 26 Condensation Particle Counters, Aerosol Sci. Tech., 27, 224-242, https://doi.org/10.1080/02786829708965469, 1997.

Wilson, C. T. R.: Condensation of Water Vapour in the Presence of Dust-Free Air and other Gases, Philos. T. Roy. Soc. Lond., 189, 265-307, 1897.

Wilson, C. T. R.: On the condensation nuclei produced in gases by the action of röntgen rays, uranium rays, ultra-violet light, and other agents, Philos. T. Roy. Soc. Lond., 192, 403-453, 1899.

Winkler, P. M., Steiner, G., Vrtala, A., Vehkamäki, H., Noppel, M., Lehtinen, K. E. J., Reischl, G. P., Wagner, P. E., and Kulmala, M.: Heterogeneous Nucleation Experiments Bridging the Scale from Molecular Ion Clusters to Nanoparticles, Science, 319, 1374 1377, https://doi.org/10.1126/science.1149034, 2008. 
Woo, K. S., Chen, D. R., Pui, D. Y. H., and McMurry, P. H.: Measurement of Atlanta Aerosol Size Distributions: Observations of Ultrafine Particle Events, Aerosol Sci. Tech., 34, 75-87, https://doi.org/10.1080/02786820120056, 2001. 